\title{
Delineation of a deletion region critical for corpus callosal abnormalities in chromosome 1q43-q44
}

\author{
Sandesh C Sreenath Nagamani ${ }^{1,8}$, Ayelet Erez ${ }^{1,8}$, Carolyn Bay $^{2}$, Anjana Pettigrew ${ }^{3}$, Seema R Lalani ${ }^{1}$, \\ Kristin Herman ${ }^{4}$, Brett H Graham ${ }^{1}$, Malgorzata JM Nowaczyk ${ }^{5}$, Monica Proud ${ }^{6}$, William J Craigen ${ }^{1}$, \\ Bobbi Hopkins $^{6}$, Beth Kozel ${ }^{7}$, Katie Plunkett ${ }^{1}$, Patricia Hixson ${ }^{1}$, Pawel Stankiewicz ${ }^{1}$, Ankita Patel ${ }^{1}$ \\ and Sau Wai Cheung ${ }^{\star 1}$
}

Submicroscopic deletions involving chromosome 1q43-q44 result in cognitive impairment, microcephaly, growth restriction, dysmorphic features, and variable involvement of other organ systems. A consistently observed feature in patients with this deletion are the corpus callosal abnormalities (CCAs), ranging from thinning and hypoplasia to complete agenesis. Previous studies attempting to delineate the critical region for CCAs have yielded inconsistent results. We conducted a detailed clinical and molecular characterization of seven patients with deletions of chromosome 1q43-q44. Using array comparative genomic hybridization, we mapped the size, extent, and genomic content of these deletions. Four patients had CCAs, and shared the smallest region of overlap that contains only three protein coding genes, CEP170, SDCCAG8, and ZNF238. One patient with a small deletion involving SDCCAG8 and AKT3, and another patient with an intragenic deletion of AKT3 did not have any CCA, implying that the loss of these two genes is unlikely to be the cause of CCA. CEP170 is expressed extensively in the brain, and encodes for a protein that is a component of the centrosomal complex. ZNF238 is involved in control of neuronal progenitor cells and survival of cortical neurons. Our results rule out the involvement of $A K T 3$, and implicate CEP170 and/or ZNF238 as novel genes causative for CCA in patients with a terminal 1q deletion.

European Journal of Human Genetics (2012) 20, 176-179; doi:10.1038/ejhg.2011.171; published online 21 September 2011

Keywords: corpus callosal abnormalities; agenesis of corpus callosum; 1q43-44 deletion; CEP170; AKT3; ZNF238

\section{INTRODUCTION}

Submicroscopic deletions involving the distal region of chromosome $1 \mathrm{q}$ result in a complex phenotype that includes growth restriction, microcephaly, craniofacial dysmorphisms, significant cognitive impairment, hypotonia, and corpus callosal abnormalities (CCAs).$^{1-6}$ CCAs, ranging from thinning and hypoplasia to complete agenesis, are consistently observed in deletions involving terminal 1q. ${ }^{1-6}$ Previous studies have suggested that the deletion of the most telomeric part of the long arm of chromosome 1, 1q43-q44, is responsible for the CCAs. However, narrowing the critical region responsible for CCAs has yielded inconsistent results. ${ }^{1,6-9}$ Boland et a $l^{8}$ mapped the deletion and translocation breakpoints in 1q44, and suggested that haploinsufficiency of AKT3 is responsible for the CCAs (Figure 1). However, Poot et a ${ }^{9,10}$ described CCAs in a patient with terminal deletion of 1q44, without involvement of AKT3. A subsequent study by van Bon et al ${ }^{1}$ narrowed the critical region for CCAs containing only Clorf100, ADSS, Clorf101, and PNAS-4. A more recent study hypothesized the gene HNRPU that is telomeric to the critical region mapped by van Bon et al ${ }^{1}$, is causative of CCAs (Figure 1). ${ }^{6}$

Using a reverse genomic approach, we sought to better understand the genotype - phenotype correlations, and map the critical region for CCAs in patients with deletion of 1q43-q44. ${ }^{11}$ The Medical Genetics
Laboratories at Baylor College of Medicine (BCM) has performed over 14000 array comparative genomic hybridization (aCGH) for clinical evaluation of subjects with developmental delay, dysmorphic features, and/or multiple congenital anomalies from June 2007 to January 2011. From this cohort of patients, we identified seven patients with deletions of 1q43-q44 including one patient with an intragenic deletion of $A K T 3$. In this report, we describe the delineation of a critical region for CCAs and show that deletion of a region spanning $\sim 930 \mathrm{~kb}$ between genomic coordinates $241054360-241522998$ and $241936310-242398193$ (NCBI36/hg18) is responsible for the CCAs (Figure 1).

\section{METHODS}

Human subjects

Identification of 1q43-q44 deletions was made by clinical diagnostic testing using aCGH. Clinical information was obtained from health care providers, using a checklist to standardize the data collection. The protocol was approved by the Institutional Review Board for human subjects' research at BCM.

\section{Array comparative genomic hybridization}

We performed aCGH analysis on the clinical microarray platform routinely used in our institution. The microarrays were designed in the Medical Genetics

\footnotetext{
${ }^{1}$ Department of Molecular and Human Genetics, Baylor College of Medicine, Houston, TX, USA; ${ }^{2}$ Department of Pediatrics, University of Kentucky, Lexington, KY, USA; ${ }^{3}$ Departments of Pathology, Pediatrics, OB/GYN and Neurology, University of Kentucky Medical Center, Lexington, KY, USA; ${ }^{4}$ Department of Pediatrics, UC Davis Medical Center, Sacramento, CA, USA; ${ }^{5}$ Departments of Pathology \& Molecular Medicine and Pediatrics, McMaster University, Hamilton, ON, Canada; ${ }^{6}$ Departments of Pediatrics and Neurology, Baylor College of Medicine, Houston, TX, USA; ${ }^{7}$ Department of Pediatrics, Washington University School of Medicine, St Louis, MO, USA

*Correspondence: Dr SW Cheung, Department of Molecular and Human Genetics, Baylor College of Medicine, 1 Baylor Plaza, NAB 2015, Houston, TX 77030, USA. Tel: +1 713798 6555; Fax: +1 713798 3157; E-mail: scheung@bcm.tmc.edu

8 These authors contributed equally to this work.
}

Received 24 February 2011; revised 19 July 2011; accepted 5 August 2011; published online 21 September 2011 


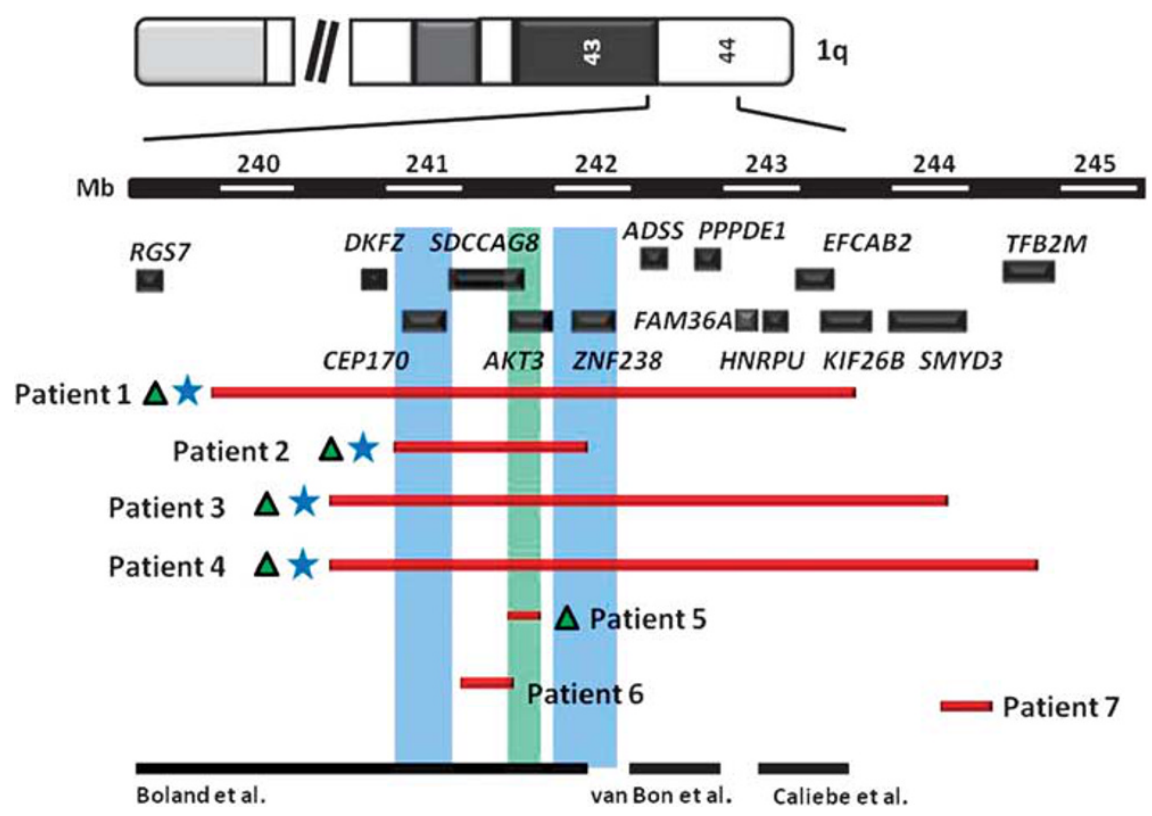

Figure 1 Size, extent, and genomic content of deletions of 1q43-q44, and mapping of critical region for CCAs and microcephaly. Upper panel depicts the ideogram of chromosome 1 with the genomic coordinates and the gene content of the 1q43-q44 region. The red bars depict the deletions in our cohort of patients, with blue stars adjacent to the bars representing the patients with CCAs, and the green triangles depicting the patients with microcephaly. The blue colored genomic interval that encompasses CEP170 and ZNF238 is the critical region for CCAs, whereas the green interval depicts that loss of AKT3 is critical for microcephaly. The previously mapped regions for CCA by Boland et $a \beta$, van Bon et $a l^{1}$ and Caliebe et $a \beta^{\beta}$ are depicted at the bottom. The deletions in patients 1-3 were confirmed to be de novo, the deletion in patient 7 was inherited from a clinically asymptomatic mother, whereas the inheritance pattern in the remaining three patients could not be ascertained.

Laboratory of BCM. All of the patient samples were interrogated using V8.OLIGO (180K). The V8.OLIGO is a custom-designed array with approximately 180000 (60 mer) interrogating oligonucleotides, manufactured by Agilent Technologies, Inc. (Santa Clara, CA, USA). This array contains the 'bestperforming' oligonucleotides (oligos) selected from Agilent's online library (eArray; https://earray.chem.agilent.com/earray/) and has been further optimized using empiric data. This array is designed to provide interrogation of all known microdeletion and microduplication syndrome regions, as well as pericentromeric and subtelomeric regions as previously described. ${ }^{12}$ In addition, 1784 genes either known to cause or hypothesized as candidate genes for various clinical phenotypes have exonic coverage with an average of 4.2 probes per exon, as well as introns greater than $10 \mathrm{~kb}$. The entire genome is covered with an average resolution of $30 \mathrm{~kb}$, excluding low-copy repeats and other repetitive sequences (https://www.bcm.edu/geneticlabs/). The procedures for DNA digestion, labeling, hybridization, and data analysis, were performed as previously described. ${ }^{13}$

\section{RESULTS}

\section{Array comparative genomic hybridization}

The deletions ranged in size from 0.08 to $4.35 \mathrm{Mb}$ (Table 1). The deletions in patients 1-3 were confirmed to be de novo, the deletion in patient 7 was inherited from a clinically asymptomatic mother, whereas the inheritance pattern in the remaining three patients could not be ascertained due to non-availability of both parental samples. All deletions involved at least a portion of the AKT3 gene, except for patient 7 . Two deletions were intragenic; the first disrupted AKT3 gene in patient 5, and the second disrupted SMYD3 gene in patient 7 (Figure 1). All deletions were confirmed by FISH analysis (data not shown). We did not detect any other copy number variations that could confound the interpretation of the data.

\section{Clinical features}

The clinical features of patients are summarized in Table 2. As the mother of patient 7 did not have phenotypic consequences, patient 7 was excluded from analysis. Patients with deletions of 1q43-q44 predominantly presented with a neuro-cognitive phenotype with developmental delay involving gross motor, fine motor, and language faculties. Microcephaly and/or structural abnormalities of the brain were observed in all, except patient 6 . CCAs ranging from severe thinning to complete agenesis were seen in patients 1 through 4 , whereas patients 5 and 6 with small deletions did not have any CCAs. Congenital heart disease in the form of atrial septal defect, Tetralogy of Fallot, and ventricular septal defect were noted in patients 3, 4, and 5, respectively. Craniofacial dysmorphic features were generally mild, with no characteristic facial gestalt.

\section{DISCUSSION}

Submicroscopic deletions involving the terminal portion of chromosome 1q43-q44 have recently emerged as a recognizable phenotype. The deletions in this region are the most common CNV associated with CCAs, and 35 patients have been reported to date. ${ }^{14}$ Previous studies attempting to map the critical region for CCAs observed with the deletions of this region have yielded inconsistent results. Boland et $a l^{8}$ studied patients with unbalanced structural rearrangements of distal 1q, and narrowed down a 3.5-Mb critical region that they hypothesized to contain the gene responsible for CCA. By further mapping of a $t(1 ; 13)(q 44 ; q 32)$ in a patient with microcephaly and CCA, they demonstrated a breakpoint mapping $20 \mathrm{~kb}$ upstream of $A K T 3$, a serine-threonine kinase, and suggested that haploinsufficiency of this gene was responsible for CCA. Orellana et al described a patient with a de novo small interstitial 1q44 deletion mapping from ADSS to KIF26B, with a mild phenotype and absence of CCA consistent with a critical region encompassing AKT3 or ZNF238 genes in corpus callosum development. Two targeted Akt 3 knockout mouse models have been described, ${ }^{15,16}$ and one demonstrated callosal hypoplasia ${ }^{16}$ with loss of both copies of $A k t 3$. These data suggested that deletion of $A K T 3$ is responsible for CCAs. 
Table 1 Molecular mapping of deletions in chromosome 1q43-q44

\begin{tabular}{|c|c|c|c|c|c|}
\hline Patient & Centromeric breakpoint & Telomeric breakpoint & $\begin{array}{l}\text { Deletion } \\
\text { size }(M b)\end{array}$ & $\begin{array}{l}\text { Genes encompassed } \\
\text { by the deletion }\end{array}$ & Inheritance \\
\hline 1 & $240640553-240683463$ & $243824577-243882928$ & 3.15 & $P L D 5 \rightarrow K I F 26 B$ & de novo \\
\hline 2 & $241014694-241054360$ & $242323495-242398193$ & 1.26 & LOC731257 $\rightarrow$ ZNF238 & de novo \\
\hline 3 & $241014694-241054360$ & $244584985-244616824$ & 4.35 & $M A P 1 L C 3 C \rightarrow S Y M D 3$ & de novo \\
\hline 4 & $240228748-241119642$ & $245037854-245059290$ & 3.93 & LOC731257 $\rightarrow$ LOC 149134 & $\begin{array}{l}\text { Mother does not have CNV, } \\
\text { father unavailable for testing }\end{array}$ \\
\hline 5 & $241833595-241843404$ & $241925842-241936310$ & 0.08 & AKT3 & Unknown \\
\hline 6 & $241505679-241522998$ & $241735307-241742028$ & 0.23 & SDCCAG8 $\rightarrow$ AKT3 & $\begin{array}{l}\text { Mother does not have CNV, } \\
\text { father unavailable for testing }\end{array}$ \\
\hline 7 & $244240651-244279769$ & $244744924-244757295$ & 0.517 & SYMD3 & Maternal \\
\hline
\end{tabular}

The data represent the location of breakpoints and the size of the deletions as assessed by V8.OLIGO.

Table 2 Clinical features of patients with deletion of 1q43-q44

\begin{tabular}{|c|c|c|c|c|c|c|}
\hline Patient & 1 & 2 & 3 & 4 & 5 & 6 \\
\hline Age (years) & 2 & 7 & 6 & 11 & 3.5 & 17 \\
\hline Sex & $\mathrm{M}$ & $\mathrm{F}$ & $\mathrm{F}$ & M & $\mathrm{F}$ & $\mathrm{F}$ \\
\hline Age at evaluation & 6 months & 2 years & 3 years & 9 years & 11 months & 7.5 years \\
\hline Reason for aCGH & $\begin{array}{l}\text { Right sex cord } \\
\text { stromal tumor, GDD }\end{array}$ & $\begin{array}{l}\text { GDD, microcephaly, } \\
\text { CCA }\end{array}$ & Microcephaly & $\begin{array}{l}\text { Microcephaly, GDD, } \\
\text { seizures, TOF }\end{array}$ & $\begin{array}{l}\text { Microcephaly, genito- } \\
\text { urinary abnormalities, } \\
\text { VSD }\end{array}$ & Mild DD \\
\hline FOC (centile) & $<3$ & $<5$ & $<5$ & $<3$ & $<3$ & 50 \\
\hline Wt (centile) & 40 & $<5$ & $<5$ & 30 & 25 & 57 \\
\hline HT (centile) & 90 & 50 & $<5$ & NA & 50 & 75 \\
\hline \multicolumn{7}{|c|}{ Cranio-facial dysmorphism } \\
\hline Head & $\begin{array}{l}\text { Microcephaly, flat } \\
\text { occiput }\end{array}$ & Microcephaly & $\begin{array}{l}\text { Microcephaly with } \\
\text { brachycephaly }\end{array}$ & Microcephaly & Microcephaly & Normal \\
\hline $\begin{array}{l}\text { Facial } \\
\text { dysmorphic } \\
\text { features }\end{array}$ & - & Hypertelorism & $\begin{array}{l}\text { Depressed nasal } \\
\text { bridge }\end{array}$ & - & + & - \\
\hline \multicolumn{7}{|l|}{ Nervous system } \\
\hline $\begin{array}{l}\text { Developmental } \\
\text { delay }\end{array}$ & GDD & GDD & GDD & GDD & GDD & Mild DD \\
\hline Seizures & + & - & - & + & - & - \\
\hline Hypotonia & + & - & - & - & - & - \\
\hline Behavioral issues & - & Aggressive & - & - & - & Anxiety \\
\hline $\begin{array}{l}\text { Structural brain } \\
\text { abnormalities }\end{array}$ & $\begin{array}{l}\text { ACC, temporal } \\
\text { pachygyria, occipital } \\
\text { polymicrogyria }\end{array}$ & $\begin{array}{l}\text { Thinning of corpus } \\
\text { callosum and hypoplasia } \\
\text { of splenium, prominent } \\
\text { cisterns with cerebral } \\
\text { volume loss }\end{array}$ & $\begin{array}{l}\text { ACC, mild simplifi- } \\
\text { cation of cerebral } \\
\text { gyri }\end{array}$ & $\begin{array}{l}\text { Severe thinning of } \\
\text { corpus callosum, small } \\
\text { cerebral hemispheres, } \\
\text { dilated subarchnoid } \\
\text { space, cerebellar } \\
\text { atrophy }\end{array}$ & None & None \\
\hline Heart & None & None & ASD & TOF & VSD & None \\
\hline $\begin{array}{l}\text { Other organ system } \\
\text { involvement }\end{array}$ & $\begin{array}{l}\text { Sex cord stromal } \\
\text { tumor }\end{array}$ & None & $\begin{array}{l}\text { Polysyndactyly of } \\
\text { toes }\end{array}$ & $\begin{array}{l}\text { Hirschsprung } \\
\text { disease }\end{array}$ & $\begin{array}{l}\text { Renal hypoplasia and } \\
\text { ureteral duplication }\end{array}$ & None \\
\hline
\end{tabular}

Abbreviations: ACC, agenesis of corpus callosum; CCA, corpus callosum abnormalities; DD, developmental delay; GDD, global developmental delay; NA, data not available, TOF, Tetralogy of Fallot; VSD, ventricular septal defect.

However, in a case report by Poot et al, ${ }^{10}$ a patient with a terminal 1q44 deletion that spared both ZNF238 and AKT3 did have CCA, implying that AKT3 may not be causative of this abnormality. van Bon et $a l^{1}$ in their cohort of 13 patients with the submicroscopic 1q43-q44 deletions delineated a region that was telomeric to and excluding AKT3, mapping from C1orf100 to PNAS-4 for CCAs. Caliebe et $a l^{6}$ showed that their cohort of four patients with a terminal $1 \mathrm{q}$ deletion and CCA shared a $0.44-\mathrm{Mb}$ region of overlap, containing the genes FAM36A, HNRPU, EFCAB2, and $K I F 26 B$, telomeric to the one mapped by van Bon et al (Figure 1). Although these studies implied that AKT3 maps outside of the region(s) critical for CCA, they do not address the question as to whether these deletions telomeric to AKT3 affect the transcription of AKT3. 
Our study reports an intragenic deletion of AKT3 in a patient with no evidence of CCAs, conclusively showing that haploinsufficiency of this gene is not responsible for this abnormality. The deletion in patient 2 is the smallest one amongst our patients with CCA. As patients 5 and 6 do not have any CCA, the region between genomic coordinates 241054360 and 241522998 , centromeric to AKT3 encompassing CEP170, and the region between 241936310 and 242398193 containing ZNF238 is likely critical for development of CCA (Figure 1). CEP170 is expressed extensively in the brain and encodes for a protein that is a component of the centrosomal complex that is involved in maintaining microtubule organization and function. Centrosomal proteins have a well-known function in neurogenesis, and have been hypothesized as important genes for the evolution of human brain size. Mutations in centrosomal proteins cause microcephaly. ${ }^{17,18}$ Recently, it has been demonstrated that centrosomal proteins are essential for microtubule organization and centrosome motility that have important roles in axonal formation. ${ }^{19}$ ZNF238 is a $\mathrm{POZ} /$ zinc finger transcriptional repressor gene. ${ }^{20}$ Mice with targeted knock out of ZNF238 display severe hypoplasia of the cerebral cortex and the hippocampus, along with increased apoptosis of progenitors in the ventricular zone. ${ }^{21}$ These functional data and the genotypephenotype correlation in our patients implicate deletion of CEP170 and/or ZNF238 as the cause for CCAs. Although our smallest region of overlap is consistent with the critical regions for CCAs previously mapped by Boland et al ${ }^{8}$ and Orellana et al, ${ }^{7}$ it is centromeric to those mapped by other studies, ${ }^{1,6,10}$ implying that the 1q43-q44 region harbors more than one gene important for the development of a normal corpus callosum.

In addition, we describe the first intragenic deletion of AKT3 and the associated phenotypic consequences that include renal abnormalities, a septal heart defect, microcephaly, and developmental delay in the absence of CCA. All patients with deletion of AKT3 had microcephaly, except patient 6 . The $\mathrm{CNV}$ in patient 6 deletes only the last exon of $A K T 3$, and hence, may lead to residual protein being translated. Although we could not confirm whether the intragenic deletion was de novo, all patients with deletion of $A K T 3$ reported to date have been observed to have microcephaly. The only report of deletion of AKT3 without any phenotypic manifestations is that of an unaffected mother of two children with microcephaly and developmental delay described by van Bon et al. ${ }^{1}$ In the same report, the only patient without microcephaly had a deletion that spared AKT3. Both of the existing knock out mouse models of Akt3 deficiency showed postnatal microcephaly. ${ }^{15,16}$ Our data interpreted, along with existing functional data, suggests that $A K T 3$ is indeed important for the normal development of the brain, but not for CCA.

In summary, deletions of 1q43-q44 result in microcephaly, developmental delay, and corpus callosal abnormalities. AKT3 is important for normal brain development, and its haploinsufficiency causes microcephaly, but not corpus callosal abnormalities. Deletion of the novel centrosomal protein $C E P 170$ and/or the zinc finger transcriptional repressor ZNF238 causes corpus callosal abnormalities.

\section{CONFLICT OF INTEREST}

The authors declare no conflict of interest.

\section{ACKNOWLEDGEMENTS}

This work was supported in part by fellowship grants by the LCRC from Osteogenesis Imperfecta Foundation (SNSC), DK081735-01A1, NIH/NIGMS T32 contract grant number GM07526 (AE).

1 van Bon BWM, Koolen DA, Borgatti R et al: Clinical and molecular characteristics of 1qter microdeletion syndrome: delineating a critical region for corpus callosum agenesis/hypogenesis. J Med Genet 2008; 45: 346.

2 van Bever Y, Rooms L, Laridon A et al: Clinical report of a pure subtelomeric 1qter deletion in a boy with mental retardation and multiple anomalies adds further evidence for a specific phenotype. Am J Med Genet A 2005; 135: 91-95.

3 Merritt II JL, Zou Y, Jalal SM, Michels VV: Delineation of the cryptic 1qter deletion phenotype. Am J Med Genet A 2007; 143: 599-603.

4 Roberts AE, Cox GF, Kimonis V, Lamb A, Irons M: Clinical presentation of 13 patients with subtelomeric rearrangements and a review of the literature. Am J Med Genet $A$ 2004; 128A: 352-363.

5 Hill AD, Chang BS, Hill RS et al: A 2-Mb critical region implicated in the microcephaly associated with terminal 1q deletion syndrome. Am J Med Genet A 2007; 143A: 1692-1698.

6 Caliebe A, Kroes HY, van der Smagt JJ et al: Four patients with speech delay, seizures and variable corpus callosum thickness sharing a $0.440 \mathrm{Mb}$ deletion in region 1q44 containing the HNRPU gene. Eur J Med Genet 2010; 53: 179-185.

7 Orellana C, Rosello M, Monfort S et al: Corpus callosum abnormalities and the controversy about the candidate genes located in 1q44. Cytogenet Genome Res 2009; 127: 5-8

8 Boland E, Clayton-Smith J, Woo VG et al: Mapping of deletion and translocation breakpoints in 1q44 implicates the serine/threonine kinase AKT3 in postnatal microcephaly and agenesis of the corpus callosum. Am J Hum Genet 2007; 81: 292.

9 Poot M, Kroes HY, VD Wijst SE et al: Dandy-Walker complex in a boy with a $5 \mathrm{Mb}$ deletion of region $1 \mathrm{q} 44$ due to a paternal $\mathrm{t}(1 ; 20)(\mathrm{q} 44 ; \mathrm{q} 13.33)$. Am J Med Genet $A$ 2007; 143A: 1038-1044.

10 Poot M, Kroes HY, Hochstenbach R: AKT3 as a candidate gene for corpus callosum anomalies in patients with 1q44 deletions. Eur J Med Genet 2008; 51: 689.

11 Bi W, Sapir T, Shchelochkov OA et al: Increased LIS1 expression affects human and mouse brain development. Nat Genet 2009; 41: 168-177.

12 El-Hattab AW, Smolarek TA, Walker ME et al: Redefined genomic architecture in $15 q 24$ directed by patient deletion/duplication breakpoint mapping. Hum Genet 2009; 126: 589-602.

13 Probst FJ, Roeder ER, Enciso VB et al: Chromosomal microarray analysis (CMA) detects a large $\mathrm{X}$ chromosome deletion including FMR1, FMR2, and IDS in a female patient with mental retardation. Am J Med Genet A 2007; 143A: 1358-1365.

14 O'Driscoll MC, Black GC, Clayton-Smith J, Sherr EH, Dobyns WB: Identification of genomic loci contributing to agenesis of the corpus callosum. Am J Med Genet A 2010; 152A: 2145-2159.

15 Easton RM, Cho H, Roovers $\mathrm{K}$ et al: Role for Akt3/protein kinase Bgamma in attainment of normal brain size. Mol Cell Biol 2005; 25: 1869-1878.

16 Tschopp O, Yang ZZ, Brodbeck D et al: Essential role of protein kinase B gamma (PKB gamma/Akt3) in postnatal brain development but not in glucose homeostasis. Development 2005; 132: 2943-2954.

17 Guernsey DL, Jiang H, Hussin J et al: Mutations in centrosomal protein CEP152 in primary microcephaly families linked to MCPH4. Am J Hum Genet 2010; 87: 40-51.

18 Popesco MC, Maclaren EJ, Hopkins J et al: Human lineage-specific amplification, selection, and neuronal expression of DUF1220 domains. Science 2006; 313 : 1304-1307.

19 de Anda FC, Meletis K, Ge X, Rei D, Tsai LH: Centrosome motility is essential for initial axon formation in the neocortex. J Neurosci 2010; 30: 10391-10406.

20 Aoki K, Meng G, Suzuki K et al: RP58 associates with condensed chromatin and mediates a sequence-specific transcriptional repression. J Biol Chem 1998; 273: 26698-26704.

21 Okado H, Ohtaka-Maruyama C, Sugitani Y et al: The transcriptional repressor RP58 is crucial for cell-division patterning and neuronal survival in the developing cortex. Dev Biol 2009; 331: 140-151. 